\title{
A CRIAÇÃO DE NEGÓCIOS POR EMPREENDEDORES JOVENS: ESTUDO DE CASOS MÚLTIPLOS NO ESTADO DE SERGIPE
}

\author{
Tomayka Mendonça Ribeiro ${ }^{1}$ \\ UFS-DAD \\ Rivanda Meira Teixeira ${ }^{2}$ \\ UFS-PROPADM
}

Resumo: A escolha do empreendedorismo jovem como tema deste estudo pode ser justificada por vários fatores, principalmente pelo fato de o Brasil ser um país de população jovem e pelo aumento da participação dos jovens em atividades empreendedoras, como mostram os dados do Global Entrepreneurship Monitor (GEM, 2011). Este estudo tem como objetivo analisar o processo de criação de negócios de jovens empreendedores sergipanos, desde a identificação da oportunidade até a consolidação do negócio, além das dificuldades enfrentadas durante esse processo. Esta pesquisa se caracteriza como exploratória e descritiva; a estratégia de pesquisa adotada foi o estudo de casos múltiplos. Os dados foram coletados por meio de entrevistas semiestruturadas com cinco empreendedores jovens, que criaram negócios no setor de serviços. As categorias analíticas e os elementos que formaram a base de análise para o estudo foram baseados na revisão da literatura. Como resultados, pode-se destacar que, de forma geral, o processo de criação de negócios pelos empreendedores jovens sergipanos não é diferente do identificado nos empreendedores mais maduros. Observa-se que foram motivados pela independência financeira, insatisfação no emprego anterior e por ter vislumbrado uma oportunidade de negócio. No entanto, a alta escolaridade desses jovens, comparada com o restante da população brasileira, é, sem dúvida, uma grande vantagem diferencial. Apesar de não possuírem alguns conhecimentos e habilidades essenciais para a gestão do negócio, os empreendedores jovens sabem onde buscá-los, estabelecem redes de contato, têm consciência de suas limitações e buscam alternativas para superá-las.

Palavras-chave: Empreendedorismo, jovens empreendedores, serviços.

\section{BUSINESS CREATION BY YOUNG ENTREPRENEURS: MULTIPLE CASE STUDIES IN SERGIPE}

Abstract: The choice of youth entrepreneurship as a focus of this study may be explained by several factors, mainly the fact that Brazil is a country of young population and the increasing youth participation in entrepreneurial activities, as shown by the data of Global Entrepreneurship Monitor (GEM, 2011). This study aims to analyze the process of business creation by young entrepreneurs in Sergipe, from identifying the opportunity to business consolidation and the difficulties faced during this process. This research is characterized as exploratory and descriptive; the research strategy adopted was the study of

\footnotetext{
${ }^{1}$ Correio eletrônico: tomayka@hotmail.com.

${ }^{2}$ Correio eletrônico: rivandateixeira@terra.com.br Endereço: Rua Humberto Pinto de Valle, n.01. CEP 49025310. Araújo/SE.
} 
multiple cases. Data were collected through semi-structured interviews with five young entrepreneurs who created businesses in the service sector. The analytical categories and the elements that formed the basis of analysis for the study emerged from the literature review. As a result, it may be noted that, in general, the process of business creation by young entrepreneurs is not different from older entrepreneurs. It is observed that they were motivated by financial independence, dissatisfaction in previous job and have glimpsed an opportunity. However, the high level of education of these young entrepreneurs, compared with the rest of the population, is undoubtedly a major advantage. Although they lack some essential knowledge and skills to manage the business, young entrepreneurs know where to get them, establish contact networks, are aware of their limitations and seek alternatives to overcome them.

Keywords: Entrepreneurship, young entrepreneurs, services.

\section{INTRODUÇÃO}

Para Schumpeter (1982), os empreendedores são responsáveis pelo desenvolvimento econômico, uma vez que promovem o rompimento da economia em fluxo circular para a economia dinâmica, competitiva e geradora de novas oportunidades. Para esse autor, a percepção e o aproveitamento de oportunidades, no âmbito dos negócios, ocasionadas pela busca de vantagens competitivas e novas conquistas, geram a inovação, uma vez que são criadas novas formas de uso de recursos, estimulando assim novas alternativas e novas oportunidades.

Bulgacov et al. (2009) destacam, nesse contexto, a expressiva presença dos jovens no panorama do empreendedorismo no Brasil, determinada pelas condições geradas pela flexibilização do mercado de trabalho e de seus reflexos nas relações sociais. É que o jovem busca, no empreendedorismo, uma alternativa de emprego e renda.

A fim de gerar comportamento empreendedor e solucionar o problema do desemprego entre os jovens brasileiros, cada vez mais a cultura empreendedora vem sendo difundida através de programas de incentivo e apoio do governo como, por exemplo, Programa Jovem Empreendedor, lançado em 2004 pelo Serviço Brasileiro de Apoio às Micro e Pequenas Empresas (SEBRAE), que tem como objetivo criar condições para que os jovens entre 16 e 24 anos de idade possam ter seu próprio negócio, eventos como a Feira do Empreendedor promovida pelo SEBRAE, e o Desafio SEBRAE, além de diversos cursos e programas criados nas universidades brasileiras para 0 ensino do 
empreendedorismo. Merecem destaque os programas lançados pela Junior Achievement Brasil, cujo objetivo é despertar o espírito empreendedor nos jovens ainda na escola, estimular o desenvolvimento pessoal e facilitar o acesso ao mercado de trabalho através de programas práticos (JÚNIOR ACHIEVEMENT, 2010). Outras iniciativas devem ser mencionadas com a filosofia de desenvolver o empreendedorismo jovem, como a criação de Confederações, Conselhos e outras entidades apoiadoras do movimento empreendedor, como a Confederação Nacional de Jovens Empresários (CONAJE) e o Conselho de Jovens Empreendedores (CJE) e, por fim, o crescimento do movimento de incubadoras no Brasil.

O empreendedorismo jovem é tema de pesquisa emergente, considerando que não possui base teórica devidamente consolidada. Soares e Machado (2005), em reflexões resultantes de seu estudo, indicam a importância de ampliar pesquisas com jovens empreendedores. Para Borges, Filion e Simard (2008), apesar de existirem diversas ações de incentivo ao empreendedorismo juvenil e do significativo aumento da participação dos jovens na criação de empresas, ainda é pouco o que se conhece sobre os jovens empreendedores.

A importância de estudar o empreendedorismo jovem advém de vários motivos. Primeiro, pelo fato de o Brasil ser um país de população jovem, com cerca de 31 milhões de habitantes nessa faixa etária de idade, o que gera o alargamento da base da pirâmide etária, de acordo com o último censo demográfico realizado em 1996 pelo Instituto Brasileiro de Geografia e Estatística (IBGE). Segundo, pelo aumento da participação dos jovens em atividades empreendedoras, como mostram os dados do Global Entrepreneurial Monitor GEM a cada ano que passa. Dados do GEM (2011) mostram que, em 2010, no Brasil, a faixa etária que obteve a mais alta taxa é aquela que vai dos 25 aos 34 anos com $22,2 \%$. Isso quer dizer que, entre os brasileiros com idades entre 25 e 34 anos, 22,2\% estavam envolvidos em algum empreendimento em 2010. A partir de 2008, os jovens de 18 a 24 anos ampliaram sua participação no universo empreendedor brasileiro. Em 2010, sem considerar a faixa etária mais empreendedora, de 25 a 34 anos, os jovens de 18 a 24 anos tiveram taxas superiores à dos brasileiros com 35 anos ou mais, demonstrando a jovialidade dos empreendedores em estágio inicial. Mais da metade, ou seja, $56,9 \%$, dos 
empreendedores ainda não estão na faixa etária de 35 anos de idade. O Brasil e a Rússia são os únicos países do G20 em que a faixa de 18 a 24 anos é mais empreendedora que a de 35 a 44 anos, após a faixa etária mais empreendedora de ambos os países, que é dos 25 a 34 anos. Ainda, se comparado ao grupo de países impulsionados pela eficiência, cuja taxa média é de $9,4 \%$, o Brasil se destaca significativamente com uma taxa $85 \%$ mais alta.

Diante do contexto apresentado, este estudo propõe-se analisar o processo de criação de negócios de jovens empreendedores sergipanos de 25 a 34 anos de idade, desde a identificação da oportunidade até a consolidação do negócio além das dificuldades enfrentadas nesse processo. Tem como objetivos específicos: a) delinear o perfil dos empreendedores jovens; b) caracterizar as empresas criadas pelos jovens empreendedores sergipanos; c) identificar os motivos que levaram os jovens empreendedores a abrir seu próprio negócio; d) verificar se houve influência da família para a criação e desenvolvimento do negócio; e) identificar os principais obstáculos enfrentados na abertura do negócio; f) verificar se foi feito um Plano de Negócios e como esse foi realizado; g) verificar as formas de financiamento utilizadas pelos jovens empreendedores; g) analisar os obstáculos para o funcionamento do negócio. Pretende contribuir e oferecer aos futuros empreendedores jovens orientações e respaldo em todas as etapas do processo empreendedor, evitando que possíveis erros sejam cometidos e garantindo, assim, o sucesso dos negócios.

\section{EMPREENDEDORISMO JOVEM}

Até a década de 80, em geral, o empreendedorismo era praticado por indivíduos adultos, após certa experiência no mercado de trabalho. Contudo, a partir da década de 90, em razão da diversidade social, ele vem sendo exercido e incentivado por outros segmentos sociais, tais como jovens e aposentados. Segundo Soares e Machado (2005), nos dias atuais, os jovens estão quebrando o paradigma de que é preciso ter certo conhecimento e experiência antes de ingressar na criação de uma empresa, uma vez que, desde cedo, cada vez mais, os jovens têm acesso às informações e aprendem a conquistar seu espaço no mercado de trabalho.

Considerando que o empreendedorismo se integra à dinâmica social, Machado 
e Gimenez (2000), a partir de uma perspectiva demográfica, de acordo com a faixa etária, consideraram fases distintas do ciclo de vida em relação ao fato de empreenderem. Para os autores, o comportamento empreendedor é diferenciado pelas seguintes tendências: a) jovens: desejo de reconhecimento e de construir a própria identidade no trabalho; b) adultos: desejo de construir algo, de fazer algo pelos outros; c) terceira idade: desejo de continuar integrado, de ser útil aos outros.

De acordo com o GEM (2011), empreendedor jovem é aquele que tem entre 18 e 34 anos e cria um novo negócio ou novo empreendimento, como, por exemplo, uma atividade autônoma, uma nova empresa ou a expansão de um empreendimento existente, que pode ocorrer de forma individual ou coletiva. Segundo Bugacov et al. (2009), nas pesquisas do GEM é observado que os países mais desenvolvidos apresentam menores taxas de participação dos jovens empreendedores quando comparadas com os países menos desenvolvidos; essa mesma relação é encontrada em outras pesquisas quando se compara a intenção do jovem no mundo do trabalho em países de diferentes níveis de desenvolvimento.

Contudo há alguns problemas a serem superados, como, por exemplo, o fato de os jovens serem confrontados com os mesmos problemas de empreendedorismo que os adultos, tais como a burocracia, taxas elevadas, falta de suporte institucional para treinamento e informação ou dificuldade de acesso a recursos, incluindo o microcrédito. Também a ausência de habilidade própria ou experiência prévia pode limitar as chances de êxito dos jovens como empreendedores. Mesmo assim, muitos países estão implantando Programas nacionais, visando estimular a criação de empresas por jovens, como, por exemplo, a Itália e Portugal (CAPALDO e FONTES, 1999).

De acordo com a OIT (2004), a colocação do jovem no mercado de trabalho deve ser vista como uma oportunidade, pois o potencial que eles representam em termos de energia, criatividade e novação são muito grandes. Já para Bulgacov et al. (2009), a atividade empreendedora, a depender das características e condições, pode tanto se caracterizar por fragilidade e exclusão, que resultarão em vulnerabilidade, como por potencialidade e espaço de realização, que devem, em nível de políticas públicas, ser estimulados. Para esses autores, compreender que a intenção empreendedora no jovem demanda identificar as características do entorno onde este jovem vive, afetando favoravelmente a intenção empreendedora. A aprendizagem se torna elemento indispensável, pois, a partir 
desse processo experimental é que os jovens amadurecem e percebem as suas habilidades, conhecimentos e motivação para empreender. Estudos recentes foram realizados sobre empreendedorismo jovem, e alguns dos seus resultados são destacados a seguir.

\subsection{ESTUDOS SOBRE EMPREENDEDORISMO JOVEM}

Estudo pioneiro sobre empreendedorismo jovem no Brasil foi realizado por Motta e Trevisan (2003), que teve como objetivo caracterizar o perfil dos jovens gaúchos quanto às características empreendedoras. A amostra constou de 47 empresas vinculadas à associação de jovens empresários de Santa Maria/RS. Com a análise dos resultados, pode-se constatar que a maioria dos entrevistados era de sexo masculino na faixa etária de 26 a 40 anos. Foi verificado que mais da metade dos entrevistados não vinha de família tradicionalmente empresária, são os fundadores do próprio negócio e estão há mais de seis anos no mercado. Assim os pesquisadores observaram que, com o devido planejamento, os empreendedores conseguiram superar as expectativas de sobrevivência das empresas superando, em média de três anos de vida as pequenas empresas.

Soares e Machado (2005), em estudo sobre as dificuldades e visão do futuro de jovens empreendedores entre 18 e 34 anos participantes do Conselho Permanente do Jovem Empresário de Maringá (COPEJEM), tiveram como objetivo conhecer a atuação de jovens no papel empreendedor. Os resultados da pesquisa mostraram que o perfil dos jovens é marcado pela elevada formação escolar, enquanto a visão reflete o desejo de crescimento dos negócios e perspectivas de melhoria tecnológica, evidenciando o potencial juvenil na criação e crescimento de empresas. Sobre as dificuldades, enfatizaram a falta de mão de obra qualificada e a dificuldade de obter recursos financeiros, principalmente.

Visando estudar o potencial empreendedor dos jovens, Machado (2005) investigou a eficácia da introdução da educação do empreendedorismo em nível universitário a partir dos fatores que definem o perfil empreendedor em termos de atitude e comportamento. Após a aplicação de questionários em uma amostra de 264 estudantes, escolhidos aleatoriamente, sugeriu que, apesar de 
haver grande interesse na atividade empreendedora, o dinheiro era a principal motivação para os alunos do curso de administração na hora de abrir um negócio. A principal conclusão identificada pelo estudo foi que a educação do empreendedorismo, em nível de ensino superior, pode ser eficaz para mudar atitudes, mas, quanto ao comportamento, pode ir além das possibilidades de uma educação em um ambiente universitário habitual.

O estudo de Bohnenberger, Schimidt e Freitas (2007) abordou a família como fator fundamental para o desenvolvimento do empreendedor, relacionado indiretamente aos fatores que influenciam os empreendedores jovens. $O$ estudo tem como objetivo verificar o quanto o contexto familiar está contribuindo para o desenvolvimento do comportamento empreendedor dos alunos dos cursos de formação superior do Centro Universitário de Feevale. A pesquisa teve como amostra 1122 estudantes da Feevale, sendo que nove questionários foram descartados por preenchimento indevido, resultando em 1113 estudantes na amostra.

Estudo realizado no Canadá sobre empreendedorismo jovem, por Borges, Filion e Simard (2008), buscou compreender o processo de criação de empresas pelos jovens empreendedores, entre 18 e 34 anos de idade, em todos os setores e regiões do Québec, Canadá. Os resultados apontaram que: 1) na maior parte dos casos, os jovens criam suas empresas em equipe; 2) eles começam com um capital inicial menor que os empreendedores de 35 anos ou mais; 3) eles precisam atravessar um processo de criação que dura, em média, mais de dois anos; 4) eles desempenham funções em todas as áreas da administração - funções para as quais têm pouca ou nenhuma formação e experiência anterior à criação da empresa.

Fonseca et al. (2008) se propuseram a explorar os fatores que influenciam a intenção de empreender dos estudantes egressos e concluintes de cursos de base tecnológica de uma grande universidade brasileira. $O$ estudo foi qualitativo, e foram realizadas sete entrevistas - quatro com alunos concludentes e três com egressos. Os resultados mostram que a categoria vontade foi apontada como um dos fatores fundamentais na influência da intenção do ato de empreender. O perfil autopercebido dos empreendedores, que corrobora a ideia de âncora de carreira, embasamento teórico do estudo, foi evidenciado como um achado empírico relevante em que a âncora de carreira 
gerencial se revelou com maior freqüência.

Santos, Minuzzi e Cruz (2010) tiveram como objetivo investigar o potencial e a propensão empreendedora em alunos de farmácia. Para isso, foram selecionados 28 estudantes cursando uma disciplina de empreendedorismo na Universidade Federal de Alagoas. Os resultados mostraram que esses alunos possuem forte potencial empreendedor; que, em relação a essa característica, não existem diferenças de gênero; que sua intenção de empreender não decorre de ter pai empreendedor; e que existe maior influência para eles empreenderem da parte dos pais que são empreendedores, quando comparados com pais não empreendedores.

Teixeira et al. (2011) realizaram estudo cujo objetivo foi analisar os fatores que influenciaram ou determinaram a trajetória de uma jovem que iniciou seu negócio aos treze anos de idade. Mais especificamente, analisou a influência da família nessa trajetória e identificou as características mais marcantes que contribuíram para seu sucesso. Essa jovem empreendedora foi escolhida para este estudo de caso, pois sua experiência singular- de iniciar um empreendimento em idade tão precoce - permite explorar novos insights sobre as características mais marcantes que influenciaram o sucesso de seu negócio. Adotou-se a estratégia de estudo de caso e utilizou-se a história de vida como técnica de coleta de dados, com a realização de entrevista em profundidade. Observou-se que a influência dos pais foi decisiva para a criação e desenvolvimento do negócio e que algumas características de empreendedores encontradas em outros estudos foram facilmente identificadas na jovem empreendedora, a exemplo de determinação, criatividade, desejo de independência, aprendizagem contínua e utilização de redes de relacionamentos.

\section{ASPECTOS METODOLÓGICOS}

Este estudo pode ser classificado como exploratório pelo fato de o tema empreendedorismo jovem ser bem recente, e só poucos trabalhos científicos foram realizados no Brasil. É também descritivo, uma vez que objetiva descrever como esses novos negócios foram criados; no entanto, como salienta Vergara (2007), não tem compromisso de explicar os fenômenos que descreve, embora sirva de base para explicá-lo. O nível de análise deste trabalho é 
organizacional, pois o objetivo é compreender a criação das empresas de jovens empreendedores no estado de Sergipe; a unidade de análise foi o empreendedor, que é o criador do novo negócio.

Para esta pesquisa, a estratégia utilizada foi o estudo de casos múltiplos. Apesar de o estudo de casos múltiplos exigir mais tempo e recursos, os resultados provenientes dessa estratégia são considerados mais convincentes e robustos (YIN, 2001). O estudo do processo de criação de novos empreendimentos por jovens sergipanos através de múltiplos casos permite maior compreensão do fenômeno a ser estudado, pois, ao analisar mais de uma empresa, novos "insights" são adicionados e maior riqueza analítica é alcançada. Com relação ao critério da escolha do caso, Yin (2001, p. 71) afirma que "qualquer aplicação da lógica de amostragem aos estudos de caso estaria mal direcionada", pois esses não se preocupam com a incidência dos fenômenos. Segundo Yin (2001), a única generalização possível é a analítica, não sendo possível a generalização estatística. Por isso, recomenda-se que o pesquisador deve escolher a amostra conforme o número de replicações de caso (literais ou teóricas) que gostaria de ter em seu trabalho.

Os entrevistados foram escolhidos por acessibilidade entre os empreendedores sergipanos que atuavam no setor de serviço. Foram utilizados como critérios de escolha empreendedores entre 25 e 34 anos de idade que tivessem um empreendimento com dois a quatro anos de existência. As entrevistas foram realizadas entre julho e agosto de 2010 com cinco empreendedores, um representante de cada empresa escolhida. Os dados foram coletados através de entrevistas pessoais que, segundo Yin (2001), constituem fontes essenciais de evidências para os estudos de caso. Foi utilizado roteiro semiestruturado de entrevistas, permitindo ao entrevistado flexibilidade em suas opiniões.

Os dados foram analisados qualitativamente, utilizando-se para isso a abordagem de análise de conteúdo que, para Bardin (2008), que utiliza procedimentos sistemáticos e objetivos de descrição do conteúdo das mensagens, porém o objetivo principal está em abstrair informações dos conteúdos após serem tratados. Todas as entrevistas foram gravadas e posteriormente transcritas. Foi feita, além da análise de conteúdo, a comparação dos casos, levando em consideração as similitudes e as diferenças 
no conteúdo de cada caso. O quadro 01 apresenta as categorias analíticas e os elementos de que formaram a base para as entrevistas e para a análise dos casos. 
Quadro 01: Categorias e elementos de análise.

\begin{tabular}{|l|l|}
\hline \multicolumn{1}{|c|}{$\begin{array}{c}\text { Categorias } \\
\text { Analíticas }\end{array}$} & \multicolumn{1}{c|}{ Elementos de Análise } \\
\hline Perfil do empreendedor & $\begin{array}{l}\text { Gênero; Naturalidade; Idade; Escolaridade; Estado civil; Renda familiar; } \\
\text { Experiência profissional. }\end{array}$ \\
\hline $\begin{array}{l}\text { Características da } \\
\text { empresa }\end{array}$ & $\begin{array}{l}\text { Estrutura do empreendimento; Número de empregados; Setor de } \\
\text { atuação; Número de sócios; Serviços/produtos oferecidos. }\end{array}$ \\
\hline $\begin{array}{l}\text { Motivos para abertura do } \\
\text { negócio }\end{array}$ & $\begin{array}{l}\text {-Oportunidade de negócio; Necessidade; Falta de emprego;Realização } \\
\text { pessoal; Outros }\end{array}$ \\
\hline Influência da família & $\begin{array}{l}\text { - Família com negócios; Familiares trabalhando no ramo; Apoio da } \\
\text { família; Tipo de apoio; Participação da família no negócio. }\end{array}$ \\
\hline $\begin{array}{l}\text { Obstáculos na criação do do } \\
\text { negócio }\end{array}$ & $\begin{array}{l}\text { - Falta de capacitação técnica; Falta de experiência; Falta de capital; } \\
\text { Contratação de empregados; Falta de apoio de amigos e familiares; } \\
\text { Dificuldade em consegui financiamento. }\end{array}$ \\
\hline Plano de Negócios & $\begin{array}{l}\text { - Planejamento inicial; Autor do planejamento; Houve ou não ajuda; } \\
\text { Pesquisa de mercado; Plano de marketing; Planejamento financeiro; } \\
\text { Utilidade; Dificuldades encontradas }\end{array}$ \\
\hline $\begin{array}{l}\text { Financiamento do } \\
\text { negócio }\end{array}$ & $\begin{array}{l}\text { - Capital próprio; Empréstimo da Família; Empréstimo bancário; } \\
\text { Dificuldades em conseguir fontes de recursos. }\end{array}$ \\
\hline $\begin{array}{l}\text { Obstáculos ao } \\
\text { funcionamento do } \\
\text { negócio }\end{array}$ & $\begin{array}{l}\text { - Falta de pessoal qualificado; Burocracia; Impostos altos; } \\
\text { Concorrência;Outros }\end{array}$ \\
\hline Situação atual do negócio & $\begin{array}{l}\text { - Ponto de equilíbrio; Lucro alto; Lucro modesto; Lucro baixo; Aumento } \\
\text { no quadro de funcionários; Parcerias; Planejamento de Marketing e } \\
\text { vendas }\end{array}$ \\
\hline
\end{tabular}

Fonte: Desenvolvido pelas pesquisadoras.

\section{ANÁLISE COMPARATIVA DOS CASOS}

A partir dos conteúdos codificados foi realizada a análise comparativa dos casos, seguindo as categorias e os elementos de análise estabelecidos na metodologia, quadro 01. Por meio dessa análise, buscou-se enfatizar as diferenças significativas $\mathrm{e}$ as similitudes apresentadas pelas organizações analisadas, bem como a comparação desses resultados com a base teóricoempírica. A primeira categoria analítica foi o perfil dos empreendedores jovens, apresentado no quadro resumo 02 nas cinco empresas do estudo. 
Quadro 02: Perfil do empreendedor

\begin{tabular}{|c|c|c|c|c|c|}
\hline $\begin{array}{l}\text { Elementos } \\
\text { de Análise }\end{array}$ & $\begin{array}{c}\text { Empresa A } \\
\text { (Hugo) }\end{array}$ & $\begin{array}{l}\text { Empresa B } \\
\text { (Alexandre) }\end{array}$ & $\begin{array}{c}\text { Empresa C } \\
\text { (Pedro) }\end{array}$ & $\begin{array}{l}\text { Empresa D } \\
\text { (Pedro Neto) }\end{array}$ & $\begin{array}{c}\text { Empresa E } \\
\text { (Elias) }\end{array}$ \\
\hline Gênero & Masculino & Masculino & Masculino. & Masculino & Masculino \\
\hline Naturalidade & $\begin{array}{c}\text { Bom Jesus da } \\
\text { Lapa/BA }\end{array}$ & Aracaju/SE & Aracaju/SE. & Aracaju/SE & Aracaju/SE \\
\hline Idade & 29 anos & 28 anos & 28 anos & 27 anos & 27 anos \\
\hline Escolaridade & $\begin{array}{l}\text { Pós- } \\
\text { graduação } \\
\text { completa }\end{array}$ & $\begin{array}{l}\text { Pós-graduação } \\
\text { completa }\end{array}$ & $\begin{array}{c}\text { Pós- } \\
\text { graduação } \\
\text { completa }\end{array}$ & $\begin{array}{l}\text { Superior } \\
\text { incompleto }\end{array}$ & $\begin{array}{l}\text { Pós- } \\
\text { graduação } \\
\text { incompleta }\end{array}$ \\
\hline Estado civil & Casado & Solteiro & Solteiro & Solteiro & Solteiro \\
\hline $\begin{array}{l}\text { Renda } \\
\text { familiar }\end{array}$ & $\begin{array}{l}4 \text { a } 6 \text { salários } \\
\text { mínimos }\end{array}$ & $\begin{array}{l}\text { Acima de } 9 \\
\text { salários } \\
\text { mínimos }\end{array}$ & $\begin{array}{l}\text { De } 7 \text { a } 9 \\
\text { salários } \\
\text { mínimos. }\end{array}$ & $\begin{array}{c}\text { De } 7 \text { a } 9 \\
\text { salários } \\
\text { mínimos } \\
\end{array}$ & $\begin{array}{l}\text { Acima de } 9 \\
\text { salários } \\
\text { mínimos }\end{array}$ \\
\hline $\begin{array}{l}\text { Experiência } \\
\text { profissional }\end{array}$ & $\begin{array}{l}\text { Teve duas } \\
\text { experiências } \\
\text { profissionais } \\
\text { em } \\
\text { Administração. } \\
\text { Esse é o } \\
\text { primeiro } \\
\text { negócio. }\end{array}$ & $\begin{array}{l}\text { Já trabalhou na } \\
\text { área de } \\
\text { hotelaria, } \\
\text { indústria e } \\
\text { marketing em } \\
\text { uma } \\
\text { seguradora. Já } \\
\text { teve outra } \\
\text { produtora e } \\
\text { uma lan house. }\end{array}$ & $\begin{array}{l}\text { Já trabalhou } \\
\text { em vários } \\
\text { lugares } \\
\text { como } \\
\text { designer } \\
\text { gráfico. } \\
\text { Esse é o } \\
\text { primeiro } \\
\text { negócio. }\end{array}$ & $\begin{array}{l}\text { Trabalhou } \\
\text { como } \\
\text { assessor } \\
\text { parlamentar e } \\
\text { coordenador } \\
\text { na área de } \\
\text { informática e } \\
\text { como } \\
\text { designer. Já } \\
\text { teve dois } \\
\text { negócios. }\end{array}$ & $\begin{array}{l}\text { Foi estagiário } \\
\text { de direito e } \\
\text { administração. } \\
\text { Já participou } \\
\text { do movimento } \\
\text { estudantil. } \\
\text { Esse é o } \\
\text { primeiro } \\
\text { negócio. }\end{array}$ \\
\hline
\end{tabular}

Fonte: Elaborado pela pesquisadora a partir dos dados coletados.

Todos os empreendedores entrevistados são do sexo masculino e, de acordo com o GEM (2011), os homens representam mais de $50 \%$ dos empreendedores no Brasil nos anos de 2002 a 2010. Ao comparar com outros estudos realizados no estado de Sergipe com os proprietários de pequenas e médias empresas no setor industrial (TEIXEIRA e BARBOSA, 2002) e no setor turístico (TEIXEIRA, 2005), vê-se a predominância do sexo masculino, pois, no primeiro estudo, observa-se que os empreendedores sergipanos correspondem a $92,3 \%$; já no segundo estudo, esse percentual é de $66,7 \%$.

Todos os entrevistados neste estudo são jovens de 27 a 29 anos, faixa etária em que se concentra a maior parte dos empreendedores brasileiros (31,7\%), segundo o GEM (2009). O estudo de Teixeira (2005), realizado no setor turístico, destaca a presença de empresários jovens. Já quando a comparação é feita com empreendedores de pequenas e médias empresas no setor industrial (BARBOSA e TEIXEIRA, 2002), observa-se que a faixa etária dos empresários é bem mais alta, pois mais de $50 \%$ se encontram entre 40 e 59 anos.

Para Filion (1999), o nível de instrução do empreendedor pode contribuir 
para que o empreendimento alcance êxito. O nível de escolaridade dos empreendedores entrevistados neste estudo pode ser considerado alto, pois a maioria já tem pós-graduação em alguma área de gestão. Somente Pedro Neto ainda não concluiu o curso superior em Publicidade. Soares e Machado (2005), no seu estudo, apontaram alguns fatores de destaque que explicam o seu grau de sucesso: o elevado nível educacional, a formação em áreas gerenciais e a inserção em uma network.

Comparando o nível de instrução com outros estudos realizados com empreendedores sergipanos, como o de Teixeira (2005) e Barbosa e Teixeira (2002), foi observado um alto nível de escolaridade, chegando a $50 \%$ os empreendedores que possuíam curso superior completo no primeiro estudo, e $50 \%$ os empreendedores que estão cursando ou já concluíram o nível superior no segundo estudo. É interessante ressaltar que somente o empreendedor da empresa $C$ não teve formação acadêmica na área de administração e gestão, o que refletiu na sua dificuldade, juntamente com seus sócios, de gerir o negócio.

Apesar de serem jovens antes de decidirem criar seu próprio negócio, todos os entrevistados afirmaram ter tido outras experiências profissionais. Essas experiências serviram para que tivessem ideia do dinamismo do mercado como um todo. Elias, da empresa E, afirmou ainda que suas experiências de estágio na época de estudante serviram para que hoje ele pudesse exercer sua liderança e as atividades administrativas dentro de sua empresa. Esse cenário também é visto em outros estudos em que afirmam que a experiência prévia do empreendedor está relacionada ao sucesso empresarial, já que o índice de empreendedores que possuem experiência profissional anterior é bastante relevante. (TEIXEIRA e BARBOSA, 2002; TEIXEIRA, 2005; BARBOSA, 2009).

Dos cinco entrevistados, nota-se que dois já tiveram outros negócios além desse, mas que não deram certo. Para Alexandre, da empresa $B$, o fator principal para o seu insucesso foram problemas com os sócios. Já em sua segunda empresa, a loja de lan house, o fechamento decorreu das mudanças no cenário, da facilidade do acesso à internet em casa, da grande concorrência e das mudanças tecnológicas que estavam ocorrendo na época. Pedro Neto, da empresa $D$, afirmou que a sua primeira empresa não deu certo por problemas com os sócios, o que gerou um desconforto; e o fechamento foi a melhor opção na época. Já em sua segunda tentativa, o fracasso foi ocasionado pela falta de 
planejamento e cuidado na hora de comprar o maquinário. A compra errada acabou gerando prejuízos. O fato de Alexandre e Pedro Neto iniciarem suas primeiras atividades empreendedoras quando ainda estavam na universidade mostra que as academias, especialmente as universidades, estão buscando, através do ensino, despertar nos estudantes uma visão de empreendedorismo, como consta no estudo de Barbosa e Teixeira (2002), que apresenta um percentual significativo $(17,5 \%)$ de empreendedores que eram estudantes antes de criarem seu negócio.

Os entrevistados afirmaram que o negócio é sua única forma de renda, o que faz com que eles se dediquem mais a ele. Somente Alexandre é operador da bolsa de valores onde consegue uma renda além do seu próprio negócio, porém essa opção foi escolhida como forma de investimento e diversão.

Os empreendedores do presente estudo são solteiros, com exceção de Hugo, da empresa A, que é casado. O mesmo é observado no estudo sobre jovens empreendedores, de Soares e Machado (2005), no qual $75 \%$ são solteiros, diferentemente do perfil geral do empreendedor, em que predomina 0 estado civil casado. O estudo de Paulino e Rossi (2003) sobre características e traços de personalidade empreendedores mostra a predominância de empreendedores casados (80\%). O quadro 03 apresenta o resumo da segunda categoria analítica que são as características das empresas. 
Quadro 03: Características das empresas

\begin{tabular}{|c|c|c|c|c|c|}
\hline $\begin{array}{c}\text { Elementos de } \\
\text { Análise }\end{array}$ & $\begin{array}{c}\text { Empresa A } \\
\text { (Hugo) }\end{array}$ & $\begin{array}{l}\text { Empresa B } \\
\text { (Alexandre) }\end{array}$ & $\begin{array}{c}\text { Empresa C } \\
\text { (Pedro) }\end{array}$ & $\begin{array}{c}\text { Empresa D } \\
\text { (Pedro Neto) }\end{array}$ & $\begin{array}{c}\text { Empresa E } \\
\text { (Elias) }\end{array}$ \\
\hline $\begin{array}{l}\text { Estrutura do } \\
\text { empreendime } \\
\text { nto }\end{array}$ & $\begin{array}{l}\text { Setor } \\
\text { Administrativo, } \\
\text { Consultoria, } \\
\text { Tecnologia e a } \\
\text { área de } \\
\text { Marketing. }\end{array}$ & $\begin{array}{l}\text { Um escritório } \\
\text { simples. }\end{array}$ & $\begin{array}{l}\text { Setor } \\
\text { administrativo } \\
\text { área técnica e } \\
\text { de produção. }\end{array}$ & $\begin{array}{l}\text { Setor } \\
\text { administrativo- } \\
\text { financeiro, setor } \\
\text { de criação, } \\
\text { produção e uma } \\
\text { pessoa no } \\
\text { atendimento e } \\
\text { caixa. }\end{array}$ & $\begin{array}{l}\text { Setor } \\
\text { Administrativ } \\
\text { o-financeiro e } \\
\text { setor de } \\
\text { projetos. }\end{array}$ \\
\hline $\begin{array}{l}\text { Número de } \\
\text { empregados }\end{array}$ & Oito & Nenhum & Três & Quatro & Cinco \\
\hline $\begin{array}{l}\text { Setor de } \\
\text { atuação }\end{array}$ & $\begin{array}{l}\text { Consultoria, } \\
\text { tecnologia e } \\
\text { marketing }\end{array}$ & Eventos & $\begin{array}{l}\text { Comunicação } \\
\text { visual }\end{array}$ & Gráfica Rápida & $\begin{array}{l}\text { Assessoria } \\
\text { em } \\
\text { formaturas }\end{array}$ \\
\hline $\begin{array}{l}\text { Número de } \\
\text { sócios }\end{array}$ & Dois & - & Dois & Dois & Dois \\
\hline $\begin{array}{l}\text { Serviços } \\
\text { oferecidos }\end{array}$ & $\begin{array}{l}\text { Pesquisa de } \\
\text { mercado, } \\
\text { consultoria em } \\
\text { gestão } \\
\text { empresarial, } \\
\text { treinamento, } \\
\text { criação de } \\
\text { website e } \\
\text { software }\end{array}$ & $\begin{array}{l}\text { Promoção e } \\
\text { produção de } \\
\text { eventos } \\
\text { voltados } \\
\text { para o } \\
\text { segmento de } \\
\text { rock }\end{array}$ & $\begin{array}{l}\text { Todo tipo de } \\
\text { serviço que } \\
\text { envolve a área } \\
\text { de } \\
\text { comunicação } \\
\text { e criação de } \\
\text { marca. }\end{array}$ & $\begin{array}{l}\text { Todo tipo de } \\
\text { serviço de gráfica } \\
\text { rápida, desde a } \\
\text { criação até a } \\
\text { impressão e } \\
\text { acabamento. }\end{array}$ & $\begin{array}{l}\text { Assessoria, } \\
\text { gestão de } \\
\text { contratos, } \\
\text { gestão } \\
\text { financeira e } \\
\text { desenvolvime } \\
\text { nto de } \\
\text { projetos. }\end{array}$ \\
\hline
\end{tabular}

Fonte: Elaborado pelas pesquisadoras a partir dos dados coletados

As empresas analisadas são microempresas e atendem a alguns dos critérios apresentados pela legislação do Simples (SEBRAE/SC, 2010), tais como: faturamento anual em até $R \$ 240.000,00$ e em caso de empresas de comércio e serviços com até nove empregados. Além disso, possuem algumas características apresentadas por Torres (1999), como: o market-share é local ou regional, os recursos humanos e financeiros são limitados, os donos ou a maior parte do negócio pertence a uma pessoa ou família, e o gerenciamento é centrado no próprio dono.

Todas as empresas têm como característica comum a estrutura física e organizacional muito simples. O setor de atuação foi o setor de serviços, o que pode ser justificado pela necessidade de menor capital inicial. Pode-se inferir que a baixa exigência em termos de complexidade organizacional é um traço característico dos microempreendimentos. No entanto, a busca pelo crescimento e pela qualidade dos serviços é comum aos cinco casos.

Quanto à originalidade da ideia do negócio, vê-se que todos os jovens empreendedores possuem uma empresa que foi constituída a partir da adaptação da ideia de outra pessoa ou imitação ou adaptação de outra 
empresa. Segundo o GEM, em 2008, o Brasil apresentou uma das mais baixas taxas de inovação de produtos, o que mostrou que o país possui empreendimentos com potencial tecnológico limitado. Em 2009, pouco mais de $15 \%$ dos empreendedores afirmaram que seu produto será reconhecido como novidade, e daí ser possível afirmar que no Brasil praticamente não existe inovação nos empreendimentos que são criados. É importante destacar que somente a empresa $A$ atua na área de tecnologia, mas apesar de situar-se no Parque Tecnológico, a empresa não foi gerada a partir de uma incubadora; o mesmo corre com as demais entrevistadas.

Um dado interessante é o fato de os jovens terem escolhido como sócias pessoas fora do vínculo familiar. Por questões fiscais, foi necessário que as empresas $D$ e $E$ registrassem um sócio representativo no contrato social para que pudessem registrar a empresa como LTDA. Somente a empresa B não possui sócio, sendo, portanto, considerada uma firma individual. Todas as empresas são consideradas como muito recentes segundo o GEM 2009, pois têm entre três a quarenta e dois meses, sendo a mais antiga a empresa $B$ que possui três anos e meio de existência.Apesar de serem microempresas e terem iniciado suas atividades com capital pequeno, todas as empresas sobreviveram e uma delas já ultrapassou o período crítico de dois anos. O quadro 04 apresenta o resumo da terceira categoria analítica, os principais motivos que levaram os empreendedores a abrir seu próprio negócio.

Quadro 04: Motivos para a abertura do negócio

\begin{tabular}{|l|c|r|r|r|r|}
\hline $\begin{array}{l}\text { Elementos de } \\
\text { Análise }\end{array}$ & $\begin{array}{c}\text { Empresa A } \\
\text { (Hugo) }\end{array}$ & $\begin{array}{c}\text { Empresa B } \\
\text { (Alexandre) }\end{array}$ & $\begin{array}{c}\text { Empresa C } \\
\text { (Pedro) }\end{array}$ & $\begin{array}{c}\text { Empresa D } \\
\text { (Pedro Neto) }\end{array}$ & $\begin{array}{c}\text { Empresa E } \\
\text { (Elias) }\end{array}$ \\
\hline $\begin{array}{l}\text { Oportunidade } \\
\text { de negócio }\end{array}$ & $\operatorname{Sim}$ & $\operatorname{Sim}$ & $\operatorname{Sim}$ & $\operatorname{Sim}$ & Sim \\
\hline Necessidade & Não & Não & Não & Não & Sim \\
\hline $\begin{array}{l}\text { Falta de } \\
\text { emprego }\end{array}$ & Não & Não & Não & Não & Não \\
\hline $\begin{array}{l}\text { Realização } \\
\text { pessoal }\end{array}$ & Não & Sim & Não & Não & Não \\
\hline Outros & $\begin{array}{l}\text { Insatisfação } \\
\text { no emprego }\end{array}$ & $\begin{array}{l}\text { Insatisfação } \\
\text { no emprego }\end{array}$ & $\begin{array}{c}\text { Independência } \\
\text { financeira }\end{array}$ & $\begin{array}{l}\text { Independência } \\
\text { financeira }\end{array}$ & Estabilidade \\
\hline
\end{tabular}

Fonte: Elaborado pelas pesquisadoras a partir dos dados coletados

Segundo Bulgacov et al. (2009), a expressiva presença dos jovens no panorama do empreendedorismo no Brasil é determinada pelas condições geradas pela flexibilização do mercado de trabalho e de seus reflexos nas relações sociais, quando o jovem busca, no empreendedorismo, alternativa de 
emprego e renda.

Ao observar as empresas, pode-se identificar que todos viram no mercado a oportunidade de abrir um negócio, porém essa não foi a única motivação. Além da oportunidade de negócio, os empreendedores foram motivados pela insatisfação que sentiam em seu emprego anterior, que os levou a procurar alternativas de renda. Somente Elias cita como motivação a busca de opções de trabalho que the dessem estabilidade, algo que não conseguia em seus estágios como estudante, já que na época atravessava um momento financeiramente difícil.

Comparando com o estudo de Borges, Filion e Simard (2008) sobre jovens empreendedores, vê-se a predominância de jovens que criaram um novo negócio porque viram uma oportunidade no mercado, bem como nos dados do GEM (2009), que destacam a motivação por oportunidade dos empreendedores brasileiros. O quadro 05 apresenta o resumo da quarta categoria analítica, a influência da família na criação de novos negócios.

Quadro 05: Influência da família

\begin{tabular}{|l|c|c|c|c|c|}
\hline $\begin{array}{c}\text { Elementos de } \\
\text { Análise }\end{array}$ & $\begin{array}{c}\text { Empresa A } \\
\text { (Hugo) }\end{array}$ & $\begin{array}{c}\text { Empresa B } \\
\text { (Alexandre) }\end{array}$ & $\begin{array}{c}\text { Empresa C } \\
\text { (Pedro) }\end{array}$ & $\begin{array}{c}\text { Empresa D } \\
\text { (Pedro Neto) }\end{array}$ & $\begin{array}{c}\text { Empresa E } \\
\text { (Elias) }\end{array}$ \\
\hline $\begin{array}{l}\text { Familiares } \\
\text { trabalhando no } \\
\text { ramo }\end{array}$ & Não & Sim & Não & Não & Não \\
\hline Apoio da família & Sim & Sim & Sim & Sim & Sim \\
\hline Tipo de apoio & $\begin{array}{c}\text { Não } \\
\text { atrapalharam }\end{array}$ & Psicológico & Financeiro & $\begin{array}{c}\text { Psicológico, } \\
\text { financeiro e } \\
\text { mão de obra }\end{array}$ & Psicológico \\
\hline $\begin{array}{l}\text { Participação da } \\
\text { família no } \\
\text { negócio }\end{array}$ & Sim & Sim & Não & Sim & Sim \\
\hline $\begin{array}{l}\text { Família com } \\
\text { negócios }\end{array}$ & Não & Sim & Sim & Sim & Sim \\
\hline
\end{tabular}

Fonte: Elaborado pela pesquisadora a partir dos dados coletados

Para Filion (1999), as pessoas apresentam mais chances de tornar-se empreendedoras se houver um modelo na família ou no seu meio; quanto mais novo for o empreendedor no início do processo, maior será a influência do ambiente familiar.

Pode-se observar que, apesar de não existir nenhum familiar que trabalha no mesmo ramo de atuação da maioria dos empreendedores entrevistados, estes afirmam ter tido algum tipo de apoio da família ao abrir seu negócio. Somente os empreendedores Pedro e Pedro Neto receberam apoio financeiro dos pais no início da criação do empreendimento. Já Elias, da empresa E, 
apesar de criar sua empresa com capital próprio, somente após o funcionamento da empresa precisou recorrer à ajuda financeira dos pais.

Os empreendedores afirmam que a cultura conservadora dos pais, na maior parte funcionários públicos, dificulta o envolvimento dos familiares quando os filhos decidem empreender; no entanto, muitos apoiam os filhos por acreditarem no sucesso do negócio. O apoio irrestrito da família ocorreu com Hugo, da empresa A, e o mesmo aconteceu com Pedro, da empresa $C$, que, no início, viu a reação de espanto dos pais quando decidiu deixar o emprego para arriscar-se a criar uma empresa com mais dois amigos; mesmo não aprovando no início, seus pais ajudaram financeiramente na abertura da empresa. Já para Alexandre, empresa B, Pedro Neto, empresa D, e Elias, empresa E, o apoio psicológico dos pais foi indispensável na criação do negócio; para Pedro Neto, além do apoio psicológico, ele recebeu apoio financeiro e ajuda de mão de obra. É importante salientar que a maioria dos empreendedores entrevistados afirmou ter pelo menos um familiar trabalhando em sua empresa, e somente Elias deu à mãe um cargo importante dentro de sua empresa. O quadro 06 apresenta um resumo da quinta categoria analítica, os principais obstáculos que surgem na criação do negócio.

Quadro 06: Obstáculos na criação do negócio

\begin{tabular}{|l|c|c|c|c|c|}
\hline \multicolumn{1}{|c|}{$\begin{array}{c}\text { Elementos de } \\
\text { Análise }\end{array}$} & $\begin{array}{c}\text { Empresa A } \\
\text { (Hugo) }\end{array}$ & $\begin{array}{c}\text { Empresa B } \\
\text { (Alexandre) }\end{array}$ & $\begin{array}{c}\text { Empresa C. } \\
\text { (Pedro) }\end{array}$ & $\begin{array}{c}\text { Empresa D } \\
\text { (Pedro Neto) }\end{array}$ & $\begin{array}{c}\text { Empresa E } \\
\text { (Elias) }\end{array}$ \\
\hline $\begin{array}{l}\text { Falta de } \\
\text { capacitação } \\
\text { técnica }\end{array}$ & Não & Não & Não & Não & Não \\
\hline $\begin{array}{l}\text { Falta de } \\
\text { experiência }\end{array}$ & Não & Não & Não & Não & Não \\
\hline Falta de capital & Sim & Não & Não & Não & Sim \\
\hline $\begin{array}{l}\text { Contratação de } \\
\text { empregados }\end{array}$ & Sim & Não & Não & Não & Não \\
\hline $\begin{array}{l}\text { Falta de apoio de } \\
\text { amigos e } \\
\text { familiares }\end{array}$ & Não & Não & Não & Não & Não \\
\hline $\begin{array}{l}\text { Dificuldade de } \\
\text { conseguir } \\
\text { financiamento }\end{array}$ & Não & Não & Não & Não & Não \\
\hline Outros & - & $\begin{array}{l}\text { Resistência a } \\
\text { mudanças }\end{array}$ & - & $\begin{array}{l}\text { Encontrar } \\
\text { boa } \\
\text { localização }\end{array}$ & $\begin{array}{l}\text { Ganhar } \\
\text { confiança do } \\
\text { mercado }\end{array}$ \\
\hline
\end{tabular}

Fonte: Elaborado pelas pesquisadoras a partir dos dados coletados

É possível observar que somente dois empreendedores apontaram falta de capital como um dos maiores obstáculos que enfrentaram na criação de seus negócios. Tal obstáculo acarretou para Hugo dificuldade na contratação de 
empregados qualificados e com perfil adequado para trabalhar em sua empresa, pois, como tinham pouco capital, Hugo, da empresa A, não tinha condições de assinar a carteira de todos os seus funcionários.

Já para Elias, além da falta de capital, a conquista da confiança do mercado foi mencionada como o maior obstáculo, pois no início a empresa $\mathrm{E}$ não tinha referência nem para os possíveis clientes nem para os fornecedores, o que fez com que os fornecedores criassem resistência para aceitar mais uma empresa que presta assessoria para formaturas. Para Alexandre, o seu maior obstáculo foi ele mesmo, porque era muito amador e não acreditava tanto em seu potencial como a sua família acreditava. Dessa forma, rejeitou muitas oportunidades logo no início de sua empresa e hoje se arrepende por não ter arriscado mais.

A maior preocupação de Pedro Neto foi encontrar para sua empresa uma localização que o satisfizesse. Buscou um local onde não tivesse necessidade de investir muito em marketing, e para isso passou mais de três meses procurando pela localização perfeita, em que até hoje se instala a empresa D. Vale ressaltar, quanto ao registro da empresa, que todos os empreendedores entrevistados afirmaram não ter tido maiores dificuldades em abrir seu negócio formalmente. Pedro ainda salienta que foi muito fácil e que, na criação, o difícil é mantê-la funcionando. $O$ quadro 07 contém um resumo da sexta categoria analítica, a realização do plano de negócios pelos empreendedores.

Quadro 07: Plano de negócios

\begin{tabular}{|l|l|l|l|l|l|}
\hline $\begin{array}{l}\text { Elementos de } \\
\text { Análise }\end{array}$ & $\begin{array}{l}\text { Empresa A. } \\
\text { (Hugo) }\end{array}$ & $\begin{array}{l}\text { Empresa B } \\
\text { (Alexandre) }\end{array}$ & $\begin{array}{l}\text { Empresa } \\
\text { C } \\
\text { (Pedro) }\end{array}$ & $\begin{array}{l}\text { Empresa D } \\
\text { (Pedro Neto) }\end{array}$ & $\begin{array}{l}\text { Empresa } \\
\text { E } \\
\text { (Elias) }\end{array}$ \\
\hline $\begin{array}{l}\text { Planejamento } \\
\text { inicial }\end{array}$ & Sim & Sim & Não & Sim & Não \\
\hline $\begin{array}{l}\text { Autor do } \\
\text { planejamento }\end{array}$ & Hugo & Alexandre & - & Pedro & - \\
\hline Houve ajuda & Não & Sim & - & Não & - \\
\hline $\begin{array}{l}\text { Pesquisa de } \\
\text { mercado }\end{array}$ & Não & Não & - & Não & - \\
\hline $\begin{array}{l}\text { Plano de } \\
\text { marketing }\end{array}$ & Sim & Sim & - & Não & - \\
\hline $\begin{array}{l}\text { Planejamento } \\
\text { financeiro }\end{array}$ & Sim & Não & - & Sim & - \\
\hline $\begin{array}{l}\text { Utilidade } \\
\text { mercado e fluxo de } \\
\text { caixa }\end{array}$ & Nenhuma & - & $\begin{array}{l}\text { Enxergar a } \\
\text { realidade } \\
\text { financeira }\end{array}$ & - \\
\hline $\begin{array}{l}\text { Dificuldades } \\
\text { encontradas }\end{array}$ & Nenhuma & Nenhuma & - & $\begin{array}{l}\text { Fazer o } \\
\text { planejamento } \\
\text { completo }\end{array}$ & - \\
\hline
\end{tabular}

Fonte: Elaborado pelas pesquisadoras a partir dos dados coletados 
Em pesquisa realizada por Bhidé (2000) com empreendedores norteamericanos, constatou-se que apenas $28 \%$ fizeram um plano de negócios, um índice baixo se comparado ao estudo de Borges, Filion e Simard (2008), feito com jovens empreendedores canadenses indicados por organizações de apoio ao empreendedor, na qual $90 \%$ dos entrevistados redigiram um plano de negócios.

Somente Hugo e Alexandre afirmaram ter feito um plano de negócios antes de abrir a empresa. No entanto alguns fizeram depois que o negócio foi iniciado. Tanto Pedro quanto Elias sentiram a necessidade de fazer um planejamento estratégico, bem como um plano financeiro e de marketing para que assim pudessem traçar estratégias expansionistas, segundo os entrevistados. Afirmaram ainda ter contratado uma empresa de consultoria para ajudá-los na elaboração do planejamento. Já Pedro Neto, apesar de não ter feito o plano de negócios, afirmou ter feito um plano financeiro, que o ajudou na criação de sua empresa e a ter um planejamento dos três primeiros meses de funcionamento. Pela experiência que tinha na época e por estar terminando a pós-graduação em Gestão Empresarial, Hugo afirmou ter feito o plano de negócios sozinho. Já Alexandre precisou da ajuda de duas professoras da universidade que pudessem corrigir e tirar as eventuais dúvidas que surgiam durante a elaboração do plano de negócios.

Quanto à utilidade das informações coletadas, somente Hugo e Pedro Neto afirmam que o plano de negócios Ihes foi útil para a abertura da empresa. Segundo Hugo, tal planejamento é útil até hoje, pois tem como acompanhar o mercado e o seu fluxo de caixa. Já Pedro Neto afirma que o planejamento financeiro Ihe foi útil a ponto de enxergar a realidade financeira de uma empresa no ramo de gráfica rápida, pois até então ele tinha uma ilusão quanto ao lucro gerado e dos possíveis custos de produção.

Alexandre foi o único a afirmar que o plano de negócios não lhe foi útil, o que fez com que ele não elaborasse um novo planejamento quando decidiu romper com os sócios e continuar o negócio sozinho. É importante ressaltar que não foi apontada nenhuma dificuldade quanto à elaboração do planejamento, porém Pedro destaca que a única dificuldade encontrada por ele foi não ter conseguido elaborar um plano de negócios completo e, sim, somente o 
planejamento financeiro. Diferentemente do estudo de Borges, Filion e Simard (2008), que constataram a grande dificuldade dos jovens canadenses de redigir o plano de negócios, principalmente no que se refere ao estudo do mercado. $O$ quadro 08 mostra o resumo da sétima categoria analítica, o financiamento do negócio.

Quadro 08: Financiamento do negócio

\begin{tabular}{|l|c|c|c|c|c|}
\hline Elementos de Análise & $\begin{array}{c}\text { Empresa A } \\
\text { (Hugo) }\end{array}$ & $\begin{array}{c}\text { Empresa B } \\
\text { (Alexandre) }\end{array}$ & $\begin{array}{c}\text { Empresa C } \\
\text { (Pedro) }\end{array}$ & $\begin{array}{c}\text { Empresa D } \\
\text { (Pedro } \\
\text { Neto) }\end{array}$ & $\begin{array}{c}\text { Empresa E } \\
\text { (Elias) }\end{array}$ \\
\hline Capital próprio & Sim & Sim & Sim & Sim & Sim \\
\hline Empréstimo da Família & Não & Não & Sim & Sim & Não \\
\hline Empréstimo bancário & Não & Não & Não & Não & Não \\
\hline $\begin{array}{l}\text { Dificuldades de } \\
\text { conseguir fontes de } \\
\text { recursos }\end{array}$ & Não teve & Não teve & Não teve & Não teve & Não teve \\
\hline
\end{tabular}

Fonte: Elaborado pelas pesquisadoras a partir dos dados coletados

Todos os empreendedores entrevistados iniciaram seu empreendimento com recursos próprios. Mas apesar de afirmarem ter começado o negócio com capital próprio, tanto Pedro quanto Pedro Neto precisaram da ajuda dos pais para financiar uma parte dos investimentos feitos na empresa. Um dado interessante a destacar é o fato de nenhum dos entrevistados recorrer a empréstimos bancários. Isso é refletido na falta da elaboração do plano de negócios, já que não precisaram ter um planejamento formal para criar a empresa, além da presença da família na criação, o que ajudou financeiramente dois dos cinco entrevistados.

Isso pode ser explicado pela escolha do setor de atuação, que não exige muito capital por serem empresas prestadoras de serviço. A dificuldade dos jovens de conseguir financiamento bancário é um fator que pode contribuir para que recorram às outras fontes de recursos, como empréstimos de familiares e amigos, ao chamado capital de proximidade (love money), como foi o caso de Pedro, Pedro Neto e Elias.

Ao comparar com outros estudos, verifica-se que, em sua maioria, os jovens iniciam seu negócio com capital próprio. No estudo feito com jovens norte-paranaenses (SOARES e MACHADO, 2005), constatou-se que 63\% abriram suas empresas com economias próprias. Já no estudo de Borges, Filion 
e Simard (2008), foi observado que $48 \%$ dos jovens recorrem à ajuda financeira da família e dos amigos, pela dificuldade que os jovens canadenses têm de conseguir financiamento bancário. O quadro 09 permite visualizar o resumo da oitava categoria analítica, os obstáculos apontados pelos empreendedores. 
Quadro 09: Obstáculos para o funcionamento do negócio

\begin{tabular}{|l|c|r|r|r|c|}
\hline $\begin{array}{c}\text { Elementos de } \\
\text { Análise }\end{array}$ & $\begin{array}{c}\text { Empresa A } \\
\text { (Hugo) }\end{array}$ & $\begin{array}{c}\text { Empresa B } \\
\text { (Alexandre) }\end{array}$ & $\begin{array}{c}\text { Empresa C } \\
\text { (Pedro) }\end{array}$ & $\begin{array}{c}\text { Empresa D } \\
\text { (Pedro Neto) }\end{array}$ & $\begin{array}{c}\text { Empresa E } \\
\text { (Elias) }\end{array}$ \\
\hline $\begin{array}{l}\text { Falta de } \\
\text { pessoal } \\
\text { qualificado }\end{array}$ & Não & Não & Não & Sim & Não \\
\hline Burocracia & Não & Não & Não & Não & Não \\
\hline Impostos altos & Não & Não & Não & Não & Não \\
\hline Concorrência & Não & Não & Não & Não & Não \\
\hline Outros & $\begin{array}{c}\text { Captação de } \\
\text { clientes }\end{array}$ & - & $\begin{array}{c}\text { Organizar a } \\
\text { empresa }\end{array}$ & $\begin{array}{c}\text { Compra de } \\
\text { suprimentos }\end{array}$ & $\begin{array}{c}\text { Possuir sede } \\
\text { própria }\end{array}$ \\
\hline
\end{tabular}

Fonte: Elaborado pelas pesquisadoras a partir dos dados coletados

Somente Pedro Neto afirmou ter tido dificuldade de encontrar pessoal qualificado para trabalhar na sua empresa; tal se deu pelo fato de ser uma área de criatividade, porém a remuneração é bem inferior ao que se paga em uma agência de publicidade. É interessante observar que somente Alexandre afirmou não ter tido nenhum tipo de dificuldade ou obstáculo para manter sua empresa funcionando. Contudo, após um tempo, por motivos pessoais e problemas com os sócios, acabou desistindo da empresa por alguns meses, mas logo retornou às suas atividades, dessa vez sem sócios.

A dificuldade na captação de clientes foi o maior obstáculo para Hugo, por não ter referências no mercado. Destaca-se ainda o fato de os empreendedores Pedro, Pedro Neto e Elias apontarem questões organizacionais como o maior obstáculo para o funcionamento de suas empresas. Tanto Pedro quanto Pedro Neto tiveram dificuldade no que se refere à administração e organização da empresa. Isso pode ser explicado pela falta de conhecimento em gestão, pois nenhum dos dois tinha qualquer curso na área quando iniciaram a empresa. Já para Elias, a maior dificuldade foi conseguir uma sede própria, já que não tinha capital, e a empresa era instalada em um escritório cedido pelo ex-chefe. O quadro 09 apresenta o resumo da nona categoria analítica, a situação atual das cinco empresas. 
Quadro 09: Situação atual do negócio

\begin{tabular}{|l|c|c|c|c|c|}
\hline \multicolumn{1}{|c|}{$\begin{array}{c}\text { Elementos de } \\
\text { Análise }\end{array}$} & $\begin{array}{c}\text { Empresa A } \\
\text { (Hugo) }\end{array}$ & $\begin{array}{c}\text { Empresa B } \\
\text { (Alexandre) }\end{array}$ & $\begin{array}{c}\text { Empresa C } \\
\text { (Pedro) }\end{array}$ & $\begin{array}{c}\text { Empresa D } \\
\text { (Pedro } \\
\text { Neto) }\end{array}$ & $\begin{array}{c}\text { Empresa E } \\
\text { (Elias) }\end{array}$ \\
\hline $\begin{array}{l}\text { Ponto de } \\
\text { equilíbrio }\end{array}$ & $\mathrm{Sim}$ & $\mathrm{Sim}$ & $\mathrm{Sim}$ & $\mathrm{Sim}$ & $\mathrm{Sim}$ \\
\hline Lucro alto & $\mathrm{Não}$ & $\mathrm{Não}$ & $\mathrm{Não}$ & Não & Não \\
\hline Lucro modesto & Não & Sim & Sim & Sim & Sim \\
\hline Lucro baixo & Sim & Não & Não & Não & Não \\
\hline $\begin{array}{l}\text { Aumento no } \\
\text { quadro de } \\
\text { funcionários }\end{array}$ & $\begin{array}{c}\text { Sim, mas já } \\
\text { reduziu }\end{array}$ & Não & Não & Sim & Sim \\
\hline Parcerias & Aprox. & $\begin{array}{c}\text { Aprox. Seis } \\
\text { para cada } \\
\text { evento }\end{array}$ & Sete & $\begin{array}{c}\text { Acima de } \\
\text { vinte }\end{array}$ & Aprox. \\
quarenta \\
\hline $\begin{array}{l}\text { Planejamento de } \\
\text { Marketing e } \\
\text { vendas }\end{array}$ & Sim & Sim & Sim & Não & Sim \\
\hline
\end{tabular}

Fonte: Elaborado pelas pesquisadoras a partir dos dados coletados

Apesar do pouco tempo de empresa, os empreendedores entrevistados afirmam ter alcançado o ponto de equilíbrio. A maioria dos entrevistados afirmou ter alcançado o ponto de equilíbrio antes dos seis meses de funcionamento, inferior ao tempo que foi constatado em outras pesquisas que apontam 37 meses (BORGES, FILION e SIMARD, 2008). Porém foi manifestada dificuldade dos empreendedores entrevistados de manter o ponto de equilíbrio.

A maioria dos entrevistados afirmou que, atualmente, o lucro de sua empresa é modesto e que possuem metas a serem atingidas; a exceção é Hugo, que considera o lucro de sua empresa baixo em consequência dos investimentos e reestruturação no quadro de funcionários que a empresa sofreu nos últimos meses. Apesar do pouco tempo de funcionamento, foi observado o desenvolvimento dos empreendedores no que se refere à gestão e ao desejo de querer expandir seus negócios. Todos os entrevistados têm não só o desejo de expandir, como já estão trabalhando para que isso ocorra.

\section{CONCLUSÕES}

A presente pesquisa buscou compreender, a partir de um estudo de casos múltiplos, como se dá o processo de criação de novos empreendimentos por jovens sergipanos. Foi constatado que os empreendedores entrevistados são do sexo masculino, têm idade média de 27 anos e são solteiros. Nasceram em Sergipe e têm alto grau de escolaridade. São graduados em Administração, Designer Gráfico, Publicidade e Direito, além de a maioria ter pós-graduação 
completa. A renda familiar dos entrevistados é relativamente alta e possuem experiências anteriores em empresas privadas, o que os ajuda a entender a dinâmica do mercado. Pode-se dizer que os empreendedores do estudo possuem as características empreendedoras citadas por Dornelas (2001), pois tiveram a iniciativa de criar um novo empreendimento, sentem paixão pelo que fazem, utilizam os recursos próprios ou de familiares.

Os empreendimentos são de microporte e do setor de serviços. Têm funcionários contratados com carteira assinada, com exceção de um empreendedor que trabalha com terceirizados. Notou-se que todos os empreendedores entrevistados criaram seu negócio a partir da imitação ou adaptação de uma ideia de outro empreendimento já existente. Os negócios foram criados com sócios, e todas as empresas são consideradas como "novas" segundo o GEM 2009, pois têm entre três a quarenta e dois meses; a mais antiga possui três anos e meio de existência.

Os empreendedores iniciaram seus negócios baseados em motivações diversas, mas em todos se observa a percepção da oportunidade de negócio. Além dessa percepção, foram motivados pela busca da independência financeira e realização pessoal, o que os levou a deixar seus antigos empregos e criar seu próprio negócio.

Apesar de a literatura ser enfática com relação à influência da família no processo de criação de novos negócios por empreendedores jovens, neste estudo não se observou tal influência. Apesar de os empreendedores jovens terem familiares com negócios, seus pais são funcionários públicos, sem tradição empreendedora. Mesmo não tendo exemplos empreendedores dos pais, todos receberam apoio da família quando decidiram criar seu próprio negócio. E, dentre os apoios oferecidos pela família, foi destacado o apoio financeiro, psicológico e até mesmo ajuda nas atividades operacionais.

A falta de capital foi o principal obstáculo para os empreendedores jovens sergipanos. A dificuldade de obter capital para realizar os desejos dos empreendedores gerou outros obstáculos, que eles tiveram que contornar como dificuldade de contratação de empregados e confiança do mercado. Foram destacados ainda o amadorismo gerencial e a dificuldade em encontrar a localização desejada para a empresa.

A exemplo do que foi observado nos demais estudos sobre 
empreendedorismo, os empreendedores jovens sergipanos não fizeram o plano de negócios para iniciar a sua própria empresa. No entanto, apesar de não terem feito esse plano no estágio inicial de preparação do negócio, o fizeram depois de a empresa ter se implantado pensando no plano como uma ferramenta de planejamento, pois reconhecem a importância do planejamento para o sucesso de sua empresa. Os elementos do plano de negócios mais relevantes para os empreendedores entrevistados foram o planejamento estratégico, plano de marketing e plano financeiro. Nenhum dos empreendedores entrevistados precisou de financiamento bancário; isso se deve ao fato de atuarem no setor de serviços e não necessitarem de investimentos altos para 0 início das suas atividades. A fonte de recursos principal para a abertura do negócio foi o capital próprio. Os empreendedores ainda tiveram a ajuda dos pais para financiar parte dos investimentos na empresa.

Foi observado que somente um entrevistado não apontou dificuldades quanto ao funcionamento de sua empresa, porém a maioria destacou fatores organizacionais como sendo os maiores obstáculos: organização da empresa, dificuldade na compra e estoque de suprimentos, captação de clientes, conquista da sede própria.

Todos os empreendimentos alcançaram o ponto de equilíbrio antes dos seis meses de funcionamento, porém enfrentam dificuldades de manter 0 equilíbrio financeiro da empresa em consequência da concorrência e da dificuldade de captação de novos clientes. O lucro da empresa é considerado pelos empreendedores como modesto, mas expressam interesse pelo crescimento e desejo de expandir o negócio. Observou-se aumento de parcerias firmadas desde a abertura da empresa, além do aumento no quadro de funcionários e existência de planejamento formal com metas e estratégias expansionistas.

Finalizando, pode-se observar que, de forma geral, o processo de criação de negócios pelos empreendedores jovens sergipanos não é diferente do identificado nos empreendedores mais maduros. Observa-se que foram motivados pela independência financeira, insatisfação no emprego anterior e por ter vislumbrado uma oportunidade de negócio. No entanto, a alta escolaridade desses jovens, comparados com o restante da população brasileira é, sem 
dúvida, uma grande vantagem diferencial. Apesar de não deterem alguns conhecimentos e habilidades essenciais para a gestão do negócio, os empreendedores jovens sabem onde buscá-los, estabelecem redes de contato, têm consciência de suas limitações e buscam alternativas para superá-los. $\mathrm{O}$ que se percebe é que esses empreendedores jovens vêm o fato de empreender como uma alternativa viável para o seu futuro e percebem a atividade empresarial muito mais atrativa do que as compensações de uma vida estável, do emprego público, que seus pais escolheram. Encaram riscos e desafios como um caminho natural a ser percorrido. Fica evidente ainda que iniciar um empreendimento no setor de serviços pode trazer vantagens, já que o empreendedor não precisa de altos investimentos nem de crédito bancário, pois empresas nesse setor possuem estrutura física e organizacional simples.

\section{REFERÊNCIAS}

BARBOSA, Jenny Dantas. Características Empreendedoras dos Empresários do Municipio de Lagarto, SE. In: Ricardo Oliveira Lacerda de Melo; Dean lee Hansen. (Org.). Ensaios Econômicos: conceitos e impasses do desenvolvimento regional. 1 ed. Aracaju: Editora UFS, 2009, v. 01, p. 325-374.

BARDIN, L. Análise de Conteúdo. Trad. Luís Antero Reto e Augusto Pinheiro. Lisboa: Edições 70 Ltda., 2008.

BHIDÉ, A. The origin and evolution of new businesses. New York: Oxford University Press, 2000.

BOHNENBERGER, M. C.; SCHMIDT, S.; FREITAS C. de. A Influência da Família na Formação Empreendedora. In: Encontro Nacional de Pós-Graduação e Pesquisa em Administração, 31, 2007 Rio de Janeiro.Anais... Rio de Janeiro:Anpad, 2007.

BORGES, Cândido; SIMARD, Germain; FILION, Louis Jacques. Jovens empreendedores e o processo de criação de empresas. Revista de Administração Mackenzie. v. 9, n. 8, Edição Especial, p. 39 - 63, nov./dez. 2008.

BULGACOV, Yára L. M.; CUNHA, Sieglinde Kindl da; CAMARGO, Denise de; MEZA, Maria Lucia. Jovens empreendedores no Brasil: a busca do espaço da realização ou a fuga da exclusão? In: 3Es2Ps - Empreendedorismo e Estratégia de Empresas de Pequeno Porte. 2009, p. 14-32. 
BULGACOV, Yára L. M.; CUNHA, Sieglinde Kindl da; CAMARGO, Denise de; MEZA, Maria Lucia. Jovens empreendedores no Brasil: a busca do espaço da realização ou a fuga da exclusão? In: 3Es2Ps - Empreendedorismo e Estratégia de Empresas de Pequeno Porte. 2009, p. 14-32.

CAPALDO, Guido e FONTES, Margarida. Young technological entrepreneurship in less developed European regions: Preliminary results of a comparative study of software firms in Portugal and Southern Italy. International Council of Small Business, ICSB, Proceedings, Nápoles, 1999.

DORNELAS, José Carlos Assis. Empreendedorismo: transformando idéias em negócios. Rio de Janeiro: Campus, 2001.

FILION, Louis Jacques. Empreendedorismo: empreendedores e proprietários-gerentes de pequenos negócios. Revista de Administração, São Paulo, v. 34, n. 2, p. 05-28, abril/junho, 1999.

FONSECA, Francisco R. Bezerra; MELLO; Sérgio Benício C. de; MARÇAL, Maria Christianni Coutinho; CORREA, Maria Iraê de Souza. Jovens empreendedores estão preparados para empreender em empresas de base tecnológica? Revista de Negócios, ISSN 1980-4431, Blumenau, v. 13, n. 3, p. 67 - 80, Julho/Setembro 2008.

GEM - Global Entrepreneurship Monitor. Empreendedorismo no Brasil 2010. Disponível em: < http://www.sebrae.com.br/>.

JÚNIOR ACHIEVEMENT BRASIL. Programas de Educação Empreendedoras. Site institucional. Disponível em: < http://migre.me/5YMpq >. Acesso em: $01 / 11 / 2010$.

MACHADO, Hilka e Gimenez, Fernando. Entrepreneurship and Diversity: a demographic approach of Brazilian cases. Proceedings 5th International Conference "Managing Global Business in the Internet Age", Beijing, 2000. MOTTA, Jeana. TREVISAN, Marcelo. Perfil de empreendedores: Associação de jovens empresários de Santa Maria/RS. SEMEAD, 7., São Paulo, Anais eletrônicos... São Paulo, 2004. Disponível em: http://migre.me/5YMBw >. Acesso em: 20/04/2010.

PAULINO, Alice Dias e ROSSI, Sonia Maria Morro. Um Estudo de Caso Sobre Perfil Empreendedor: características e traços de personalidade empreendedora. In: EGEPE - Encontro de Estudos Sobre Empreendedorismo e Gestão de Pequenas Empresas. 3, 2003, Brasília. Anais... Brasília: UEM/UEL/UnB, 2003, p. 205-220.

SCHUMPETER, Joseph Alois. Teoria do desenvolvimento econômico. São Paulo, Abril Cultural, 1982. 
SEBRAE/SC. Critérios de classificação de empresas ME - EPP. Disponível em: <http://www.sebrae-sc.com.br/leis/default.asp?vcdtexto=4154>. Acesso em: $01 / 11 / 10$.

SOARES, Michel André Felippe; MACHADO, Hilka Pelizza Vier. Jovens empreendedores: perfil, dificuldades na gestão e perspectivas dos empreendimentos. In: EGEPE - encontro de estudos sobre empreendedorismo e gestão de pequenas empresas. 4. 2005, Curitiba, Anais... Curitiba, 2005, p. 305-312.

TEIXEIRA, Rivanda Meira et al. Empreendedorismo Jovem e a Influência da Família: a história vida de uma empreendedora de sucesso. In: Revista de Gestão - REGE, São Paulo - SP, Brasil, v. 18, n.1, p 3-18, jan/mar. 2011.

TEIXEIRA, Rivanda Meira. Diagnóstico de Pequenos Negócios Hoteleiros em Sergipe. In: TRIGO, Luis Gonzaga Godoi (editor). Análises Regionais e Globais do Turismo Brasileiro. São Paulo: Roca, 2005

TEIXEIRA, Rivanda Meira; BARBOSA, Jeny Dantas. Pequenas e Médias Indústrias de Sergipe: diagnóstico de gestão. Aracaju: SEBRAE, 2002. TORRES, O. Les PME. France: Flammarion, 1999.

VERGARA, Sylvia Constant. Projetos e relatórios de pesquisa em administração.9 ed. São Paulo: Atlas, 2007.

YIN, Robert K. Estudo de caso: planejamento e métodos. Porto Alegre: Bookman, 2001. 